\title{
Homing of human autoreactive $T$ cells into pancreatic tissue of NOD-scid mice
}

Received: 24 March 2004 / Accepted: 9 August 2004 / Published online: 24 December 2004

(C) Springer-Verlag 2004

\begin{abstract}
Aims/hypothesis: An important prerequisite for the initiation of pancreatic islet inflammation is the recruitment of pathogenic $\mathrm{T}$ cells. We investigated the in vivo migration patterns of human islet-reactive $T$ cell clones after transfer into compromised hosts. Methods: NOD-scid mice were injected with a mixture of human autoreactive T cells and antigen-presenting cells. Survival and migration of $\mathrm{T}$ cells was analysed by fluorescenceactivated cell sorter and immunohistochemical analysis of various tissues. Results: Autoreactive T cells and antigenpresenting cells survived at least 14 days in vivo and accumulated in spleen, pancreatic tissue and pancreas draining lymph nodes, but not elsewhere, as early as 4 days after transfer. This homing was dependent on co-injection of human antigen-presenting cells loaded with autoantigen. Finally, we found that this process is enhanced by streptozotocin treatment. Streptozotocin treatment did not affect the constitutive homing to pancreas draining lymph nodes. Histological analysis of pancreatic tissue sections showed some autoreactive $\mathrm{T}$ cells around the islets of Langerhans, comparable to early peri-islet insulitis. However, the majority of pancreas-infiltrating $\mathrm{T}$ cells accumulated around blood vessels in the exocrine pancreas. All T cell clones expressed the chemokine receptor CXCR3 that is associated with homing to insulitic lesions in men and mice. Conclusions/interpretation: Our study provides the first evidence of in vivo accumulation in pancreatic tissue of islet-reactive $\mathrm{T}$ cells derived from type 1 diabetic patients. The fact that such $\mathrm{T}$ cells do not penetrate islets is in line with the concept that additional factors may be required for the entry of $\mathrm{T}$ cells into inflamed islets to become diabetogenic.
\end{abstract}

\footnotetext{
A. G. S. van Halteren · M. J. Kardol · A. Mulder ·

B. O. Roep ( $\square)$

Department of Immunohematology and Blood Transfusion, E3Q, LUMC,

PO Box 9600, 2300 RC Leiden, The Netherlands

e-mail: boroep@lumc.nl

Tel.: +31-71-5263800

Fax: +31-71-5216751
}

Keywords Chemokine receptors · Inflammation · Lymphocyte homing $\cdot$ T-Lymphocytes $\cdot$ Type 1 diabetes

Abbreviations APC: Antigen-presenting cells - CCR: Chemokine receptor - CXCR: Chemokine receptor . FACS: Fluorescence-activated cell sorter - GAD65: Glutamic acid decarboxylase $65 \mathrm{kDa} \cdot \mathrm{HSP}$ : Heat shock protein - NOD: Non-obese diabetic mouse - PBMC: Peripheral blood mononuclear cells - PDLN: Pancreas draining lymph nodes $\cdot$ PI: Propidium iodide

\section{Introduction}

In humans and in the NOD mouse strain, type 1 diabetes is preceded by leucocyte infiltration of the pancreatic islets of Langerhans (insulitis) followed by destruction of the insulin-producing beta cells by autoimmune $T$ cells [1] We and others have demonstrated the presence of circulating autoreactive human $\mathrm{CD} 4^{+} \mathrm{T}$ cells as well as $\mathrm{CD}^{+} \mathrm{T}$ cells $[2,3]$ around the clinical onset of type 1 diabetes. Moreover, T-cell-directed therapies were found to preserve beta cell function [2], suggesting the contribution of autoreactive $T$ cells to the pathogenesis of type 1 diabetes.

Analysis of insulitis development in NOD mice demonstrated that $\mathrm{CD} 4^{+} \mathrm{T}$ cells predominate in the early phase, followed by an influx of $\mathrm{CD} 8^{+} \mathrm{T}$ cells [4]. However, both $\mathrm{CD}^{+}$and $\mathrm{CD}^{+}{ }^{+} \mathrm{T}$ cells are required for the initiation of beta cell destruction after adoptive transfer into NOD-scid mice [5]. Moreover, injection of an islet-specific $\mathrm{CD} 4^{+} \mathrm{T}$ cell clone was found to accelerate diabetes in young NOD mice [6]. Thus, a signal derived from $\mathrm{CD}^{+} \mathrm{T}$ cells seems to be required for efficient accumulation of autoreactive $\mathrm{T}$ cells in islets of Langerhans [7, 8].

We have previously cloned autoreactive $\mathrm{CD}^{+} \mathrm{T}$ cells from a recent-onset type 1 diabetic patient [9] and from a pre-diabetic patient who developed type 1 diabetes 2 years after isolation of the clone [10]. The relevance of such autoreactive $\mathrm{T}$ cells in human insulitis and the beta cell destruction process remains unresolved. To extend our 
knowledge on these islet-reactive $\mathrm{T}$ cells, we aimed to study their homing capacity to pancreatic tissue of NODscid mice in relation with their chemokine receptor expression. These recipient mice were shown to allow functional engraftment of human leucocytes without severe signs of graft-vs-host disease [11, 12]. Moreover, autoantigens associated with type 1 diabetes as well as murine chemokines and chemokine receptors display a very high sequence homology between man and mouse. We therefore analysed the fate of both $\mathrm{T}$ cell clones, injected either separately or together.

Since early antigen exposure was shown to be a prerequisite for prolonged survival and function of human $\mathrm{T}$ cells in scid mice [12], we co-injected peptide-pulsed antigen-presenting cells (APC). In addition, we determined the contribution of streptozotocin-induced beta cell stress to the migration pattern of autoreactive $\mathrm{T}$ cells and analysed their chemokine receptor expression in situ.

\section{Materials and methods}

Animals Male NOD-scid mice (FOX CHASE SCIDNOD) aged 4-6 weeks were obtained from M\&B (Ry, Denmark). Mice were housed under specific pathogen-free conditions in micro-isolator cages and were fed sterilised water and autoclaved chow. Experiments and maintenance of the mice were approved by the Animal Ethics Committee of the University of Leiden. Recipient mice received five consecutive daily i.p. injections of low-dose $(40 \mathrm{mg} / \mathrm{kg}$ ) streptozotocin to induce hyperglycaemia $[13,14]$ and autoantigen release from damaged islets [15]. Control mice received vehicle only. Human cells were injected into the mice 1 day after the last streptozotocin injection. Hyperglycaemia was monitored by FreeStyle teststrips in combination with a FreeStyle glucometer (Disetronic, Vianen, The Netherlands) and was diagnosed when blood glucose levels exceeded $11 \mathrm{mmol} / \mathrm{l}$ on repeated measurements.

Reconstitution of NOD-scid mice with human cells Human peripheral blood mononuclear cells (PBMC) were isolated by Ficoll gradient from buffy coats obtained from healthy blood donors selected on the basis of their HLA type. Tcell-depleted APC were obtained by using Dynabeads Pan Mouse IgG beads precoated with $10 \mu \mathrm{g} / \mathrm{ml}$ mouse antihuman CD3 antibody (CLB, Amsterdam, The Netherlands), according to the manufacturer's protocol (Dynal Biotech, Hamburg, Germany). Monocyte and B-cellenriched APC $\left(<10 \% \mathrm{CD}^{+}\right.$T cells) were pulsed for $3 \mathrm{~h}$ at $37^{\circ} \mathrm{C}$ and $5 \% \mathrm{CO}_{2}$ in IMDM medium (Gibco Life Technologies, Breda, The Netherlands) supplemented with $5 \%$ pooled human serum and $6 \mu \mathrm{mol} / 1$ relevant peptide, depending on the $\mathrm{T}$ cell clone(s) used for reconstitution. After peptide pulsing, APC were washed with sterile PBS and mixed in a 1:1 ratio with equal numbers of T cells. In some experiments, monocyte-derived dendritic cells, generated as previously described [16], were used as APC and mixed in a 1:10 ratio with $T$ cells. The stimulatory capacity of injected APC was routinely checked by culturing $2 \times 10^{4}$ mixed cells for 4 days in a standard proliferation assay as described previously [16]. In most reconstitution experiments, APC were mismatched for HLA-A determinants for identification purposes as described below.

Three different $\mathrm{T}$ cell clones were used for reconstitution experiments: a glutamic acid decarboxylase $65 \mathrm{kDa}$ (GAD65)-specific autoreactive $\mathrm{T}$ cell clone (PM1\#11), which recognises the GAD65 epitope $\mathrm{p}(339-352)$ in the context of HLA-DR3 [10]. Additionally, these T cells express HLA-A1/A26 and HLA-B8/B57. The second islet-specific autoreactive $\mathrm{T}$ cell clone (1C6) recognises insulin secretory granules or $38-\mathrm{kDa}$ antigen [9] and a peptide epitope $\mathrm{p}(51-70)$ in the context of HLA-DR1 [17]. Additionally, these T cells express HLA-A2/A3 and HLAB39/B44. The third $\mathrm{T}$ cell clone (N3A9; HLA-DR1 restricted) was isolated from a tuberculoid leprosy patient and recognises $\mathrm{p}(412-425)$ of the $65-\mathrm{kDa}$ heat shock protein (hsp) of M. leprae [18]. Murine and human hsp60, a candidate autoantigen in type 1 diabetes, both contain this exact amino acid sequence. Additionally, these T cells express HLA-A10/A26 and HLA-B5/B51. Both autoreactive $\mathrm{T}$ cell clones were expanded for $8-12$ days by $0.5 \%$ phyto-haemagglutinin (HA16, Murex Biotech, Dartford, UK) in the presence of 3000 rd-irradiated pooled feeder cells, whereas clone N3A9 was expanded with $0.15 \mu \mathrm{mol} / 1$ M. leprae sonicate in the presence of 2000 rd irradiated HLA-DR1 matched PBMC. Resting T cells $\left(10 \times 10^{6} \%\right.$ mouse) were harvested and washed before mixing with APC and $0.5 \mathrm{ml}$ of this mix was injected i.p. in each recipient mouse. Typically, three mice were analysed in each experimental group. Results are expressed as mean percentage detected $\mathrm{T}$ cells $\pm \mathrm{SD}$. NOD-scid mice expressing $\geq 1 \%$ circulating mouse $\mathrm{CD}^{+} \mathrm{T}$ cells were excluded from the experiments.

Evaluation of chimerism The prevalence of human leucocytes was evaluated by flow cytometry [fluorescenceactivated cell sorter (FACS) Calibur] using APC-conjugated mouse anti-human CD3 antibody (BD Biosciences, Amsterdam, The Netherlands) on single cell suspensions prepared from various organs or peritoneal lavage fluid. To exclude aspecific staining of murine $\mathrm{Fc} \gamma \mathrm{R}^{+}$cells or dead cells, samples were counterstained with propidium iodide (PI) and PE-labelled rat anti-mouse CD45 (BD Biosciences). In some experiments, T cells were double-labelled with a specific human HLA-A1 monoclonal antibody followed by PE-labelled rabbit anti human $\operatorname{IgM~} \mathrm{F}(\mathrm{ab})_{2}$ (Dakopatts, Älvsjö, Denmark). To check for T cell proliferation in vivo, cloned $\mathrm{T}$ cells were labelled with $0.5 \mu \mathrm{mol} / \mathrm{ml}$ CFDA-SE (Molecular Probes, Leiden, The Netherlands) prior to infusion.

The presence of human T cells or APC in the pancreas, spleen and pancreas draining lymph nodes (PDLN) was analysed in $8-\mu \mathrm{m}$ cryostat sections, which were fixed in $100 \%$ acetone and stained with mouse anti-human CD3 antibody (Dakopatts), followed by Alexa Fluor 488conjugated goat anti-mouse IgG1 (Molecular Probes). To discriminate cloned $\mathrm{T}$ cells from contaminating $\mathrm{T}$ cells 
present in the APC fraction, double-labelling was performed with specific human monoclonal HLA antibodies (HuMAbs) followed by Alexa Fluor 594-conjugated goat anti-human IgG (Molecular Probes). Hybridomas producing HuMAbs were developed by electrofusion of EBVtransformed cell lines generated from the lymphocytes of multiparous females with serum HLA antibodies. HLA specificities of these antibodies were determined by screening complement-mediated cytotoxicity against large panels $(n>240)$ of serologically HLA-typed individuals. HuMAbs were used as hybridoma supernatants. The following HuMAbs were used: SN230G6 (IgG; anti HLA-A2/B17) and VDK1D12 (IgM; anti HLA-A1/A36). All antibodies and conjugates were diluted in $\mathrm{PBS} / 2 \% \mathrm{FCS}$ and were tested negatively on tissue sections prepared from naïve NOD-scid mice (data not shown). Immediately after staining, sections were analysed on a Nikon Eclipse E800 microscope containing a Nikon DXM 1200 digital camera and Nikon ACT-1 software.

Chemokine receptor expression by cloned $T$ cells The expression of various chemokine receptors was determined on viable $\left(\mathrm{PI}^{-}\right) \mathrm{T}$ cells by FACS analysis using various PE-labelled antibodies (BD Biosciences). Additionally, CXCR3 and CCR4 expression was determined in situ on $8-\mu \mathrm{m}$ cryostat sections prepared from spleen and pancreas of reconstituted mice. Briefly, sections were simultaneously stained with human anti-human HLA-A2 antibody and mouse anti-human CXCR3, CXCR4 or CCR4 antibody (BD Biosciences), followed by Alexa Fluor 488-conjugated goat anti mouse IgG1 and Alexa Fluor 594-conjugated goat anti-human IgG (Molecular Probes) as described above.

\section{Results}

Cloned human autoreactive T cells survive at least 14 days after intraperitoneal reconstitution of NOD-scid mice To determine the survival of human autoreactive T cells upon i.p. transfer into NOD-scid mice, we analysed the presence of human $\mathrm{CD}^{+} \mathrm{T}$ cells in peritoneal lavage fluids of mice killed at 7 (Fig. 1a, c) or 14 (Fig. 1b) days after reconstitution with CFSE-labelled $38-\mathrm{kDa}$ antigen-specific $\mathrm{T}$ cells and CD3-depleted PBMC. Within the total fraction of viable cells, $\mathrm{CD}^{+} / \mathrm{CFSE}^{-}(1.8 \pm 0.5 \%)$ as well as $\mathrm{CD}^{+} /$ $\mathrm{CFSE}^{+}(5.1 \pm 1.9 \%) \mathrm{T}$ cells were recovered from the peritoneal cavity at day 14 after infusion (Fig. 1). The latter population displayed a variable level of CFSE expression, indicative of $\mathrm{T}$ cell proliferation in vivo.

We next analysed the origin of the $\mathrm{CD}^{+} \mathrm{T}$ cells recovered from the peritoneal cavity (Fig. 1c) by using a specific HLA-A1 antibody that discriminates contaminating $\mathrm{T}$ cells in the injected APC fraction (HLA-A $1^{+}$) from the autoreactive $\mathrm{T}$ cell clone (HLA-A1 ${ }^{-}$). The mean percentage of contaminating, i.e. HLA-A1 ${ }^{+}{ }^{-}$cells was 12.9 $\pm 1.9 \%$ within the recovered fraction of $\mathrm{CD}^{+} / \mathrm{PI}^{-}$cells, demonstrating that the majority of human $\mathrm{T}$ cells recovered originated from the injected $\mathrm{T}$ cell clone.
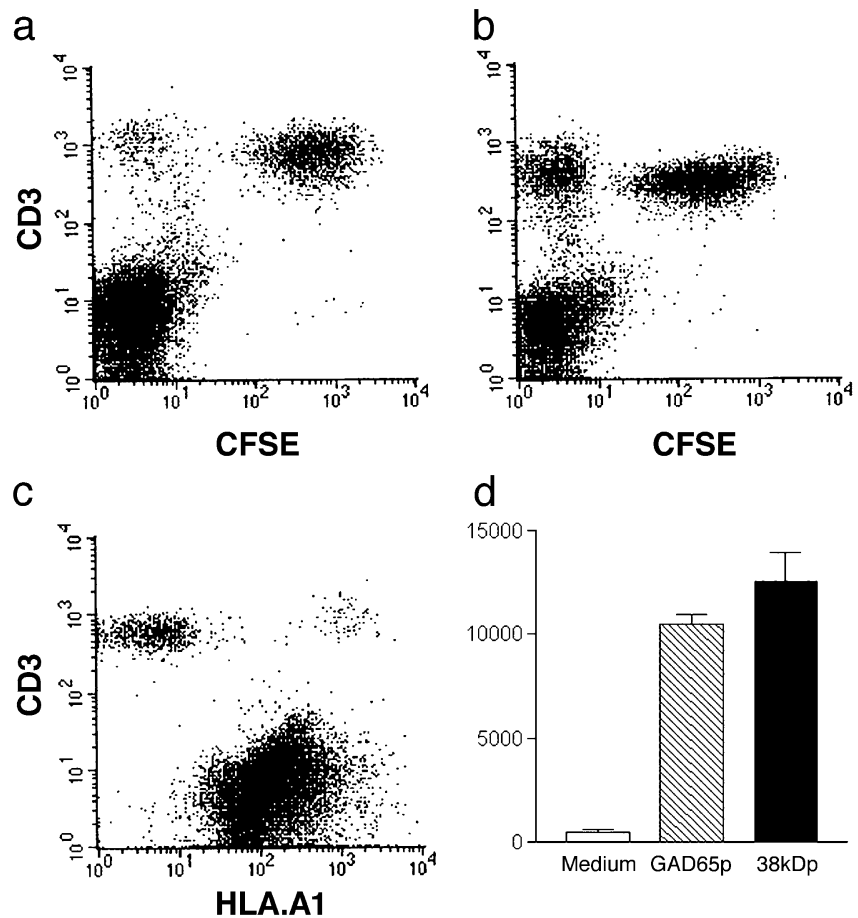

Fig. 1 Survival and function of human 38-kDa-specific $\mathrm{T}$ cells upon intraperitoneal injection into NOD-scid mice. Peritoneal lavages were performed at 7 (a, c, d) or 14 days (b) after reconstitution of NOD-scid mice with CFSE $(\mathbf{a}, \mathbf{b})$ or non-labelled $(\mathbf{c}, \mathbf{d})$ autoreactive $\mathrm{T}$ cells. After this, we determined the presence of human $\mathrm{CD}^{+} \mathrm{T}$ cells in the $\mathrm{PI}^{-} /$mouse $\mathrm{CD} 45^{-}$population. To discriminate autoreactive $\mathrm{T}$ cells (HLA-A ${ }^{-}$) from contaminating $\mathrm{T}$ cells $\left(\mathrm{HLA}-\mathrm{Al}^{+}\right)$in the APC population, double staining was performed for human CD3 and HLA-A1 (see Materials and methods). d The proliferative capacity of $\mathrm{T}$ cells recovered from a recipient mouse that had been injected with two different autoreactive T cell clones in a 1:1 ratio. Peptide-pulsed monocytes expressing both restriction elements were used as APC. Results are shown as mean proliferation $(\mathrm{cpm})$ of triplicate cultures $\pm \mathrm{SD}$

In separate mice, we addressed the survival of GAD65specific $\mathrm{T}$ cells upon co-administration with $38-\mathrm{kDa}-$ specific $\mathrm{T}$ cells (Fig. 1d). At 7 days after transfer, both autoreactive $\mathrm{T}$ cell clones were viable and retained the capacity to respond upon in vitro co-culture with new peptide-pulsed APC. These results demonstrate that the $\mathrm{T}$ cells had not become anergic, probably due to cotransferred peptide-pulsed APC [12]. Thus, antigenic stimulation and appropriate co-stimulatory signals induce proliferation and/or survival of autoreactive human T cells upon injection into the peritoneal cavity.

Cloned human autoreactive $T$ cells express CXCR3, a chemokine receptor associated with $T$ cell infiltration in insulitis The expression of various chemokine receptors associated with type 1 diabetes (CCR5, CXCR3 [19-21]), with various sites of inflammation (CCR1, CCR4 and CXCR6) or with homing to $\mathrm{T}$ cell zones in lymphoid organs (CCR7 [22], CXCR4 [23]) was analysed on the two islet-specific autoreactive $\mathrm{T}$ cell clones (1C6 and PM1\#11) as well as on the hsp60-specific $\mathrm{T}$ cell clone (Fig. 2). All T cells expressed CXCR3, CXCR4 and low 

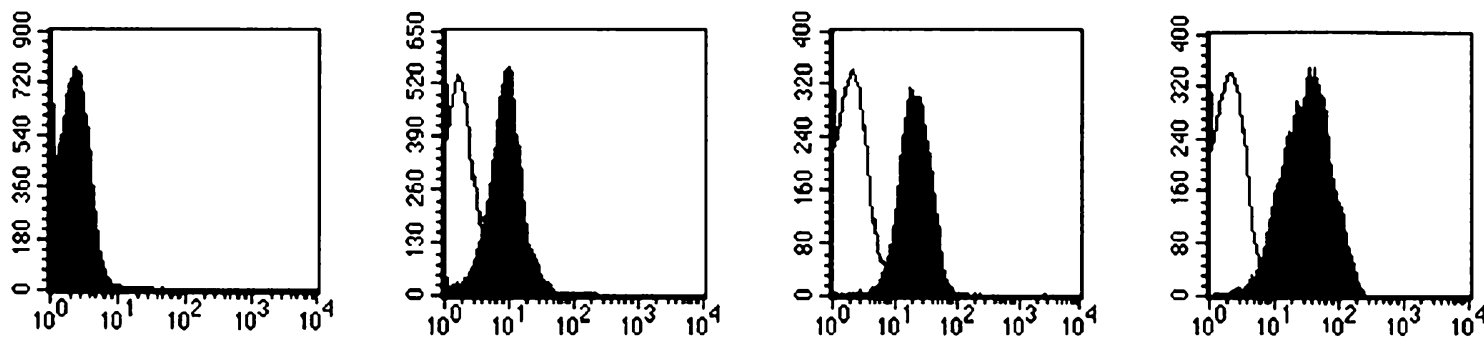

$1 \mathrm{C} 6$
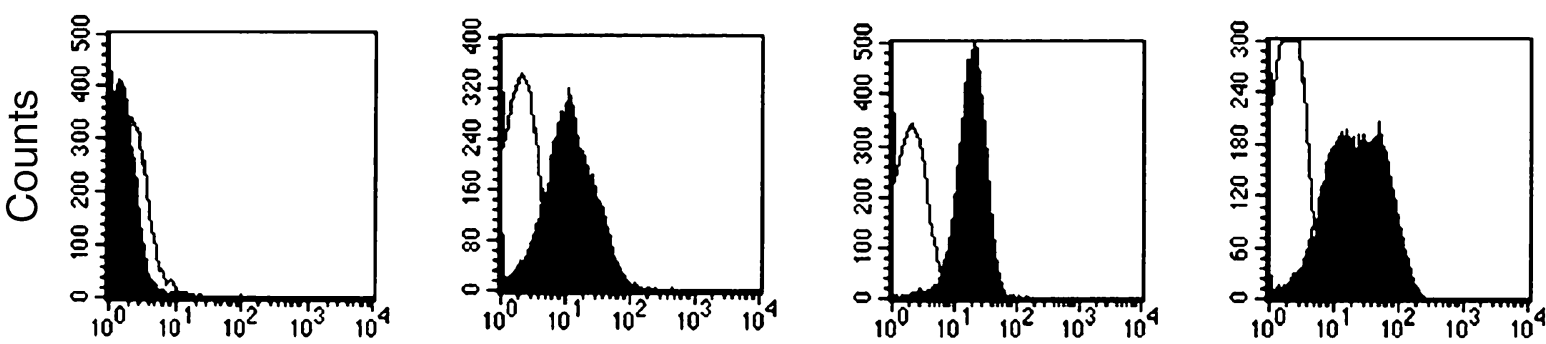

PM1\#11
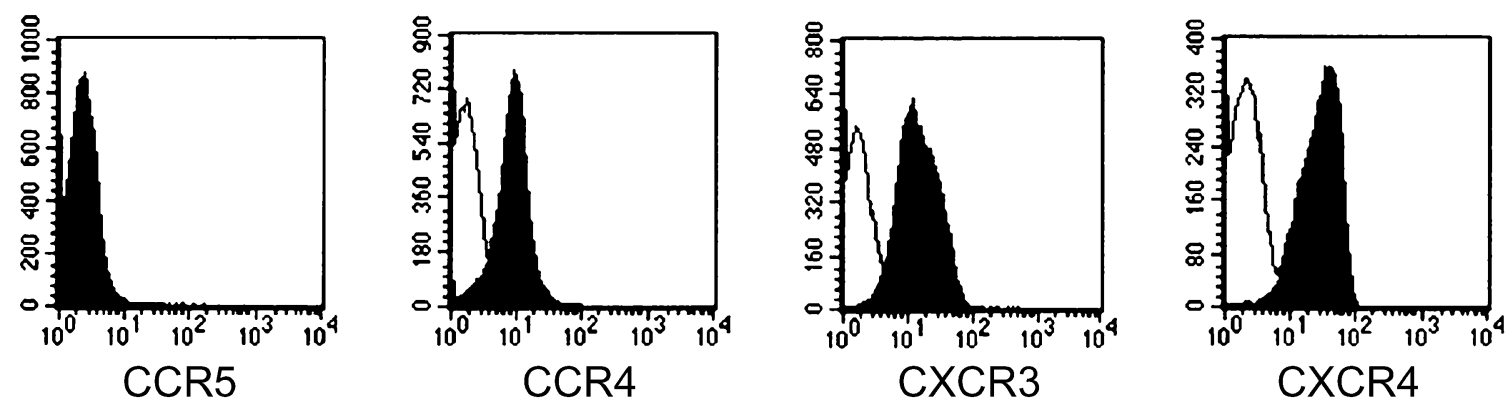

N3A9

Fig. 2 Chemokine receptor expression by cloned human autoreactive T cells (clone 1C6 or PM1\#11) or by a cross-reactive $\mathrm{T}_{\mathrm{H}} 1 \mathrm{~T}$ cell clone reactive to bacterial hsp60 of $M$. leprae and mice (N3A9)

levels of CCR4. Expression of CXCR6, CCR1, CCR7 (data not shown) and CCR5 could not be detected. Thus, all $\mathrm{T}$ cell clones express the CXCR3 chemokine receptor associated with $\mathrm{T}_{\mathrm{H}} 1$ inflammation in general $[20,24]$ and with homing to inflamed islets in particular, as well as CXCR4, a chemokine receptor associated with homing to the white pulp of the spleen [25].

Homing of human autoreactive $T$ cell clones to murine pancreatic tissue and other organs The presence of human $\mathrm{CD}^{+} \mathrm{T}$ cells in frozen tissue sections prepared from pancreata and other organs isolated at 7 or 14 days after reconstitution with $38-\mathrm{kDa}$-specific autoreactive $\mathrm{T}$ cells was analysed (Fig. 3a). Few $\mathrm{T}$ cells were observed adjacent to blood vessels in the interstitial connective tissue between the pancreatic lobuli when APC pulsed with autoantigen were co-administered. Human T cells could not be detected in peripheral (axillar and brachial) lymph nodes or liver (Table 1). However, in view of the high number of cells, the sensitivity of the FACS technique on whole liver suspensions may be too low for detection of human T cells. A previous study on the engraftment of human peripheral blood lymphocytes has, however, reported that $\mathrm{CD}^{+}$cells can be detected in liver from 4 weeks post i.p. injection onwards [26]. T cells were detected in spleen $(0.2 \pm 0.07 \%)$ and PDLN $(23.7 \pm 8.1 \%)$.
Similar experiments were performed with GAD65specific $T$ cells. These $T$ cells could not be traced in the pancreas, liver or peripheral lymph nodes, despite similar survival in the peritoneal cavity (Fig. 1). Accumulation of both $\mathrm{T}$ cell clones was, however, observed in pancreas draining lymph nodes $(8.6 \pm 1.9 \%)$ and spleen $(0.3 \pm 0.1 \%)$.

We next studied whether streptozotocin pretreatment of recipient NOD-scid mice would augment the influx of human $\mathrm{T}$ cells (Table 1). We were able to detect increased numbers of 38-kDa-specific T cells in the interstitial tissue (Fig. 3b), as well as around, but never within the islets of Langerhans (data not shown). Few GAD65-specific T cells were found in the pancreas when transferred into streptozotocin-treated mice, comparable to levels observed after transfer of 38-kDa-specific $\mathrm{T}$ cells into untreated mice (data not shown). We additionally tested the composition of the infiltrates by double staining the sections for CD3 and HLA-A1 antibodies (Fig. 3c). The majority of infiltrating cells stained positive for CD3 but not for HLA-A1, representing the injected $\mathrm{T}$ cell clone 1C6 (HLA-A $\left.1^{-} / \mathrm{A}^{+}\right)$, whereas few cells stained double positive (yellow) representing contaminating $\mathrm{T}$ cells from the $\mathrm{APC}$ fraction $\left(\mathrm{CD}^{+}, \mathrm{HLA}-\mathrm{A} 1^{+}\right)$. Thus, the pancreatic infiltrates mainly consisted of infiltrating $\mathrm{T}$ cell clones as well as antigen-presenting cells. Control experiments were performed to test the contribution of antigenic stimulation 

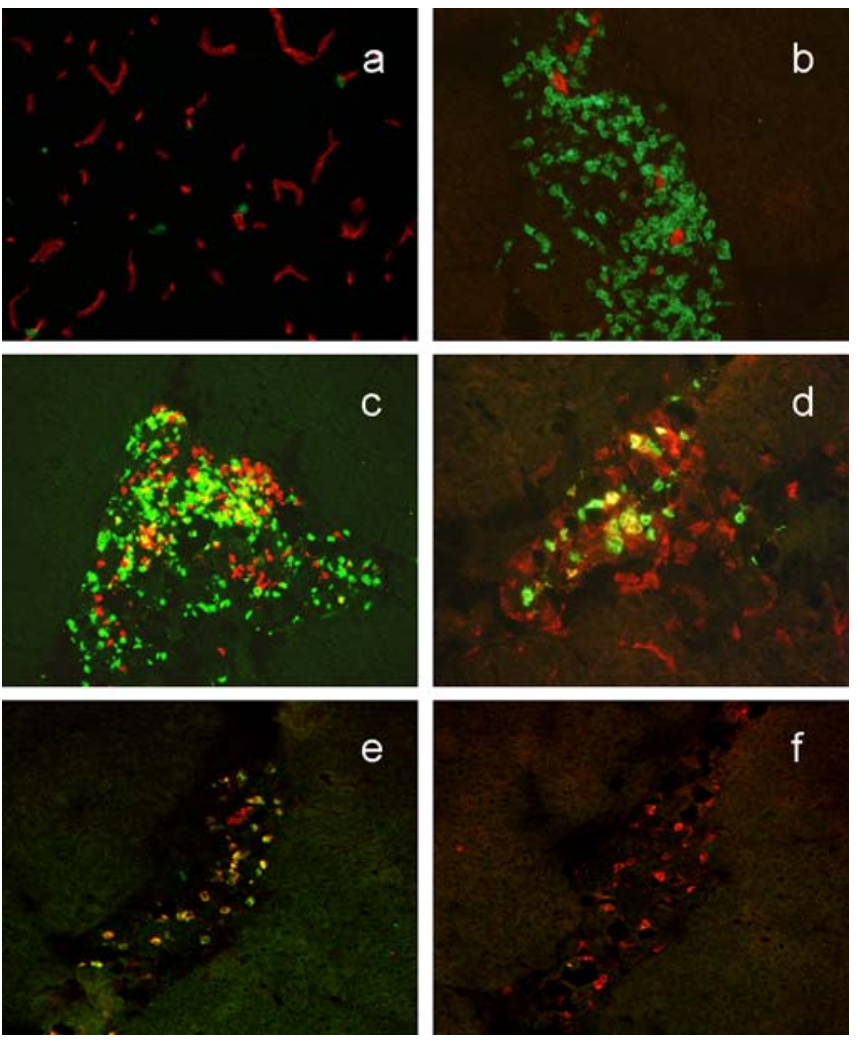

Fig. 3 Analysis of the homing pattern of autoreactive $T$ cells to murine pancreatic tissue. NOD-scid mice were pretreated with vehicle (a) or streptozotocin (b-f) prior to intra-peritoneal reconstitution with human islet-reactive T cells. Reconstituted mice were killed at $4(\mathbf{e}, \mathbf{f}), 7(\mathbf{c}, \mathbf{d})$ or $14(\mathbf{a}, \mathbf{b})$ days after infusion. Frozen pancreatic tissue sections were prepared and stained with various antibodies: human CD3-expressing 38-kDa-specific T cells in green and mouse endothelial cells in red (MECA-32 [48], 400×) (a, b); human CD3-expressing 38-kDa-specific T cells in green, HLA-A1expressing T cell-depleted APC in red and contaminating HLA-A $1^{+}$ T cells from APC fraction in yellow $(200 \times)(\mathbf{c})$; human HLA-A1 ${ }^{-}$CD3 expressing 38-kDa-specific T cells in green, HLA-A $1^{+}$dendritic cells in red and HLA-A $1^{+} \mathrm{CD} 3$-expressing GAD65-specific T cells in yellow $(400 \times)($ d); human CXCR3 (e) or CCR4-expressing cells (f) in green in combination with HLA-A2 ${ }^{+}$-expressing $38-\mathrm{kDa}-$ specific T cells in red $(200 \times)$

to homing into the pancreas of streptozotocin-treated hosts. For this, 38-kDa-specific T cells were co-injected with GAD65 peptide-pulsed APC. Analysis of spleen and pancreas demonstrated the presence of only a few scattered $\mathrm{T}$ cells, which could be detected by histological techniques only (data not shown). Collectively, these results show that optimal homing of human autoreactive $\mathrm{T}$ cells into the pancreas is dependent on proper antigenic stimulation in vivo, as well as on streptozotocin pretreatment of the host.

After this we analysed the fate of both $\mathrm{T}$ cell clones that had been injected together with dendritic cells expressing both restriction elements and the relevant peptides (Fig. $3 \mathrm{~d})$. We hypothesised that recruitment of $38-\mathrm{kDa}$-specific $\mathrm{T}$ cells into pancreatic tissue could perhaps improve the poor migration of GAD-65-specific T cells. We consistently observed a dominant influx of $\mathrm{CD}^{+} / \mathrm{HLA}^{-} \mathrm{A}^{-} 38$ $\mathrm{kDa}$-specific $\mathrm{T}$ cells (green) and lower, but clearly detectable numbers of yellow staining $\mathrm{T}$ cells $\left(\mathrm{CD}^{+} /\right.$ HLA-A $1^{+}$), representing GAD65-specific $\mathrm{T}$ cells. We also studied the homing of the CXCR3-expressing crossreactive hsp60-specific $\mathrm{T}$ cells (HLA-A2 ${ }^{-}$) in vivo by co-injecting this clone with $38-\mathrm{kDa}$-specific T cells (HLA$\left.\mathrm{A} 2^{+}\right)$. Both $\mathrm{T}$ cell clones were detected in the pancreas (data not shown). Collectively, these results suggest that 38-kDa-specific T cells improve pancreatic accumulation of poorly homing autoreactive as well as hsp60-specific $\mathrm{T}$ cells derived from a nondiabetic individual.

Finally, we analysed the expression of CXCR3 and CCR4 in pancreatic tissue collected 4 days after reconstitution, when the first infiltrating $\mathrm{T}$ cells were observed (Fig. 3e, f). A few $\mathrm{CXCR}^{+}$but HLA-A2 ${ }^{-}$cells could be detected in situ, but the majority of the cells stained yellow, representing HLA-A2 and CXCR3 expressing 38$\mathrm{kDa}$-specific $\mathrm{T}$ cells. None of the recruited cells were found to express CCR4.

\section{Discussion}

This is the first report on in vivo migration characteristics of two islet-reactive $\mathrm{T}$ cell clones isolated from patients before or at clinical onset of type 1 diabetes. We demonstrate that NOD-scid mice are suitable hosts for long-term, i.e. a minimum of 3 weeks, reconstitution with human $\mathrm{T}$

Table 1 Migration pattern of two different human autoreactive T cell clones after transfer into NOD-scid mice

\begin{tabular}{|c|c|c|c|c|}
\hline $\begin{array}{l}\text { Specificity of } \mathrm{T} \text { cell clone } \\
\text { Host pretreatment }\end{array}$ & $\begin{array}{l}\text { GAD65 } \\
\text { Vehicle }\end{array}$ & $\begin{array}{l}\text { GAD65 } \\
\text { Streptozotocin }\end{array}$ & $\begin{array}{l}38 \mathrm{kDa} \\
\text { Vehicle }\end{array}$ & $\begin{array}{l}38 \mathrm{kDa} \\
\text { Streptozotocin }\end{array}$ \\
\hline Spleen ${ }^{\mathrm{a}, \mathrm{b}}$ & + & + & + & + \\
\hline Liver $^{\mathrm{a}}$ & - & - & - & - \\
\hline Peritoneal lavage $^{\mathrm{a}}$ & ++ & ++ & ++ & ++ \\
\hline Pancreas $^{\mathrm{b}}$ & - & \pm & \pm & ++ \\
\hline Pancreas draining $\mathrm{LN}^{\mathrm{a}, \mathrm{b}}$ & ++ & ++ & ++ & ++ \\
\hline Peripheral $\mathrm{LN}^{\mathrm{a}}$ & - & - & - & - \\
\hline
\end{tabular}

$-<0.1 \%$ of total cells, \pm few cells visualised by histological techniques only, $+<1 \%$ of total cells, $++>1 \%$ of total cells, $L N$ lymph nodes Various organs were analysed by FACS ${ }^{\mathrm{a}}$ or by histology ${ }^{\mathrm{b}}$ for the presence of human $\mathrm{CD}^{+} \mathrm{T}$ cells. Organs were collected 14 days after intraperitoneal reconstitution of vehicle- or streptozotocin-pretreated NOD-scid mice with $10 \times 10^{6} \mathrm{~T}$ cell clone and equal numbers of T-celldepleted, peptide-pulsed PBMC. Autoreactive T cells were double-stained with specific HLA-A antibodies. 
cell clones, providing that peptide-pulsed APC are coadministered. Our study shows constitutive homing of both $\mathrm{T}$ clones to PDLN and spleen, but variable accumulation in the pancreas. Recruitment into pancreatic tissue was clearly augmented after pretreatment of recipient mice with streptozotocin, but this treatment did not result in infiltration of islets of Langerhans.

Extravasation of lymphocytes from the circulation into organs or inflamed tissue is a multistep process involving recognition and specific interactions of adhesion molecules on these cells with their endothelial counter receptors. GAD65-reactive peripheral blood lymphocytes from type 1 diabetes patients were found to express $\alpha 4 \beta 7$ integrin, which is known to bind the mucosal addressin MAdCAM-1 [27]. Mucosal lymphoid organs preferentially express MAdCAM-1 on high endothelial venules [28]. MAdCAM-1 is also expressed in inflamed islets of NOD mice and human diabetic pancreas $[29,30]$ and was shown to mediate pancreatic homing of murine $\mathrm{T}$ cells [31]. In prediabetic mice, MAdCAM-1 is constitutively expressed in the exocrine tissue and on vessels adjacent to but not inside the islets [32]. This expression pattern matches the observed accumulation of human islet-reactive $\mathrm{T}$ cells in our study, i.e. in exocrine tissue and occasionally around the islets. Thus despite the fact that streptozotocin pretreatment is thought to be associated with immunogenic alterations in islets [15], this is probably not sufficient to induce entry of human autoreactive $\mathrm{T}$ cells. Interferon- $\gamma$ may be an important factor involved in the induction of MAdCAM-1 expression in islets of Langerhans [33]. Experimental diabetes models using different IFN $\gamma$-deficient mice have shown that this cytokine is crucial in controlling the homing of diabetogenic $\mathrm{T}$ cells into islets $[34,35]$. In the absence of IFN $\gamma$, diabetogenic $\mathrm{T}$ cells accumulate in the exocrine tissue or at the islet vascular isthmus, comparable to the histological results presented in this study.

Interferon- $\gamma$ is also an important inducer of chemokine release by stressed pancreatic islets or beta cells [20,36,37]. Chemokines and their receptors are thought to play an important role in lymphocyte traffic. Chemokines mediate local inflammatory responses by their ability to recruit $\mathrm{T}$ cells and other cells of the immune system, providing that these cells express certain chemokine receptors [38]. Several chemokine receptors have been associated with recruitment of $\mathrm{T}_{\mathrm{H}} 1 \mathrm{~T}$ cells to sites of inflammation [39]. The contribution of CCR5 to the pathogenesis of autoimmune diabetes in NOD mice was indirectly demonstrated by reduced insulitis and protection from diabetes in NOD. MIP- $1 \alpha^{-/-}$mice, the chemokine that binds to CCR5 [19]. A contribution of CXCR3 as well as CCR4 in autoimmune diabetes or pancreatic infiltration has also been documented $[20,40,41]$. In recent-onset type 1 diabetes patients, a temporary reduction of peripheral $\mathrm{CD}^{+} / \mathrm{CD}^{+} \mathrm{T}$ cells expressing $\mathrm{T}_{\mathrm{H}} 1$-associated chemokine receptors CXCR3 and CCR 5 was demonstrated [42]. These results suggest a role for these receptors in recruitment of autoreactive $\mathrm{T}$ cells into the inflamed pancreas. Our observed CXCR3 expression in situ is in line with the earlier studies impli- cating this chemokine receptor in directing murine autoreactive $\mathrm{T}$ cell to inflamed pancreatic tissue. Two known ligands for CXCR3, i.e. CXCL10 [43] and CXCL9 [44], have been shown to be involved in diapedesis of human and circulating effector $\mathrm{T}$ cells [36]. Moreover, murine CXCL10 shares a high amino acid sequence identity with human CXCL10 and is known to bind to the human CXCR3 receptor [45].

Both human islet-reactive T cells and the hsp60-specific $\mathrm{T}$ cell clone were found to express equal levels of the CXCR3 chemokine receptor in vitro. Yet, our results point out differences in pancreatic accumulation between the $T$ cell clones. Perhaps the $38-\mathrm{kDa}$-specific $\mathrm{T}$ cells upregulate other integrins or chemokine receptors in vivo, which may improve pancreatic homing compared to the other human $T$ cells tested, even in the absence of pancreatic inflammation. Alternatively, $\mathrm{T}$ cell homing to the pancreas under non-inflammatory conditions may be biased by the absence or presence of the relevant autoantigens. It is conceivable that the unique granular localisation of $38-\mathrm{kDa}$ antigen drives pancreatic homing of these $\mathrm{T}$ cells based on steady-state activity of beta cells, i.e. exocytosis of insulin.

The hsp60-specific $\mathrm{T}$ cell clone was found in the pancreas after co-transfer with $38-\mathrm{kDa}$-specific $\mathrm{T}$ cells in streptozotocin-pretreated mice. These results are in line with observations in prediabetic NOD mice, demonstrating that homing of lymphocytes to pancreatic islets is not restricted to autoreactive $\mathrm{T}$ cells [33]. Moreover, the peptide epitope recognised by the these T cells resides in a conserved region of heat shock protein 65 , a protein produced under conditions of (beta) cell stress and associated with insulitis and type 1 diabetes [2]. Like hsp60-specific T cells, GAD65-specific T cells could only be traced in the pancreas when co-injected with $38-\mathrm{kDa}$-specific $\mathrm{T}$ cells. This poor accumulation could be explained by the fact that the GAD65-specific $T$ cell clone requires autoantigenpresentation by HLA-DR ${ }^{+}$endothelial cells for optimal migration across human vascular endothelium [46]. Unstimulated $\mathrm{T}$ cells do not transmigrate, suggesting that only appropriately stimulated autoreactive $\mathrm{T}$ cells reach the endocrine islet mass.

In contrast to variable homing to pancreatic tissue, both islet-specific autoreactive $\mathrm{T}$ cell clones accumulated to a similar extent in the pancreas draining lymph nodes. Beta cell insult, i.e. after viral infection in RIP-LCMV transgenic mice, was recently shown to induce a CXCL10 gradient between the pancreas (low expression) and its draining lymph node (high expression) [47]. Such a gradient is perhaps also present in hyperglycaemic streptozotocin-treated NOD-scid mice and may recruit human $\mathrm{T}$ cells away from the pancreas into the pancreas draining lymph nodes.

Collectively, our results demonstrate that autoreactive $T$ cells derived from type 1 diabetic patients home to the pancreatic islet environment, but may require additional signals to enter the islets. As yet, we have no evidence that these $T$ cells destroy pancreatic islets in vivo. Nevertheless, on the basis of their homing characteristics, we 
conclude that these human T cells fulfil a critical primary checkpoint for participation in the pathogenesis of type 1 diabetes.

Acknowledgements The work described here was funded by grant 2000.00.056 of the Diabetes Fund Nederland. We thank Dr. N.E. Annels (Leiden University Medical Centre) for providing the chemokine receptor antibodies for immunohistology, Prof. T.H.M. Ottenhof (Leiden University Medical Centre) for supplying $\mathrm{T}$ cell clone N3A9, Dr. R.E. Mebius (Vrije Universiteit Amsterdam) for providing the MECA-32 antibody and Prof. F.H.J. Claas for critical reading of the manuscript. Gabriëlle Pinkse is gratefully acknowledged for her expert technical assistance.

\section{References}

1. Atkinson MA, Maclaren NK (1994) The pathogenesis of insulin-dependent diabetes mellitus. N Engl J Med 331:14281436

2. Roep BO (2003) The role of T-cells in the pathogenesis of Type 1 diabetes: from cause to cure. Diabetologia 46:305-321

3. Panina-Bordignon P, Lang R, van Endert PM et al (1995) Cytotoxic $\mathrm{T}$ cells specific for glutamic acid decarboxylase in autoimmune diabetes. J Exp Med 181:1923-1927

4. Bedossa P, Bendelac A, Bach JF, Carnaud C (1989) Syngeneic $\mathrm{T}$ cell transfer of diabetes into NOD newborn mice: in situ studies of the autoimmune steps leading to insulin-producing cell destruction. Eur J Immunol 19:1947-1951

5. Christianson SW, Shultz LD, Leiter EH (1993) Adoptive transfer of diabetes into immunodeficient NOD-scid/scid mice. Relative contributions of CD4+ and CD8+ T-cells from diabetic versus prediabetic NOD.NON-Thy-1a donors. Diabetes 42:4455

6. Haskins K, McDuffie M (1990) Acceleration of diabetes in young NOD mice with a CD4+ islet-specific T cell clone. Science 249:1433-1436

7. Thivolet C, Bendelac A, Bedossa P, Bach JF, Carnaud C (1991) $\mathrm{CD} 8+\mathrm{T}$ cell homing to the pancreas in the nonobese diabetic mouse is CD4+ T cell-dependent. J Immunol 146:85-88

8. Verdaguer J, Schmidt D, Amrani A, Anderson B, Averill N, Santamaria P (1997) Spontaneous autoimmune diabetes in monoclonal $\mathrm{T}$ cell nonobese diabetic mice. J Exp Med 186:1663-1676

9. Roep BO, Arden SD, de Vries RR, Hutton JC (1990) T-cell clones from a type-1 diabetes patient respond to insulin secretory granule proteins. Nature 345:632-634

10. Schloot NC, Batstra MC, Duinkerken G et al (1999) GAD65reactive $\mathrm{T}$ cells in a non-diabetic stiff-man syndrome patient. $\mathrm{J}$ Autoimmun 12:289-296

11. Greiner DL, Shultz LD, Yates J et al (1995) Improved engraftment of human spleen cells in NOD/LtSz-scid/scid mice as compared with C.B-17-scid/scid mice. Am J Pathol 146:888-902

12. Cao T, Leroux-Roels G (2000) Antigen-specific $T$ cell responses in human peripheral blood leucocyte (hu-PBL)mouse chimera conditioned with radiation and an antibody directed against the mouse IL-2 receptor beta-chain. Clin Exp Immunol 122:117-123

13. Like AA, Rossini AA (1976) Streptozotocin-induced pancreatic insulitis: new model of diabetes mellitus. Science 193:415-417

14. Gerling IC, Friedman H, Greiner DL, Shultz LD, Leiter EH (1994) Multiple low-dose streptozocin-induced diabetes in NOD-scid/scid mice in the absence of functional lymphocytes. Diabetes 43:433-440

15. Weide LG, Lacy PE (1991) Low-dose streptozocin-induced autoimmune diabetes in islet transplantation model. Diabetes 40:1157-1162
16. Van Halteren AG, van Etten E, de Jong EC, Bouillon R, Roep BO, Mathieu C (2002) Redirection of human autoreactive Tcells upon interaction with dendritic cells modulated by TX527, an analog of 1,25 dihydroxyvitamin $\mathrm{D}(3)$. Diabetes 51:21192125

17. Neophytou PI, Roep BO, Arden SD et al (1996) T-cell epitope analysis using subtracted expression libraries (TEASEL): application to a $38-\mathrm{kDa}$ autoantigen recognized by $\mathrm{T}$ cells from an insulin-dependent diabetic patient. Proc Natl Acad Sci U S A 93:2014-2018

18. Ottenhoff TH, Mutis T (1990) Specific killing of cytotoxic T cells and antigen-presenting cells by CD4+ cytotoxic $\mathrm{T}$ cell clones. A novel potentially immunoregulatory T-T cell interaction in man. J Exp Med 171:2011-2024

19. Cameron MJ, Arreaza GA, Grattan M et al (2000) Differential expression of CC chemokines and the CCR5 receptor in the pancreas is associated with progression to type I diabetes. J Immunol 165:1102-1110

20. Frigerio S, Junt T, Lu B et al (2002) Beta cells are responsible for CXCR3-mediated T-cell infiltration in insulitis. Nat Med 8:1414-1420

21. Lohmann T, Laue S, Nietzschmann U et al (2002) Reduced expression of Th1-associated chemokine receptors on peripheral blood lymphocytes at diagnosis of type 1 diabetes. Diabetes 51:2474-2480

22. Campbell JJ, Bowman EP, Murphy K et al (1998) 6-C-kine (SLC), a lymphocyte adhesion-triggering chemokine expressed by high endothelium, is an agonist for the MIP-3beta receptor CCR7. J Cell Biol 141:1053-1059

23. Bleul CC, Farzan M, Choe H et al (1996) The lymphocyte chemoattractant SDF-1 is a ligand for LESTR/fusin and blocks HIV-1 entry. Nature 382:829-833

24. Yuan YH, ten Hove T, The FO, Slors JF, van Deventer SJ, te Velde AA (2001) Chemokine receptor CXCR3 expression in inflammatory bowel disease. Inflamm Bowel Dis 7:281-286

25. Hargreaves DC, Hyman PL, Lu TT et al (2001) A coordinated change in chemokine responsiveness guides plasma cell movements. J Exp Med 194:45-56

26. Hoffmann-Fezer G, Gall C, Zengerle U, Kranz B, Thierfelder S (1993) Immunohistology and immunocytology of human T-cell chimerism and graft-versus-host disease in SCID mice. Blood 81:3440-3448

27. Paronen J, Klemetti P, Kantele JM et al (1997) Glutamate decarboxylase-reactive peripheral blood lymphocytes from patients with IDDM express gut-specific homing receptor alpha4beta7-integrin. Diabetes 46:583-588

28. Nakache M, Berg EL, Streeter PR, Butcher EC (1989) The mucosal vascular addressin is a tissue-specific endothelial cell adhesion molecule for circulating lymphocytes. Nature 337: 179-181

29. Hanninen A, Taylor C, Streeter PR et al (1993) Vascular addressins are induced on islet vessels during insulitis in nonobese diabetic mice and are involved in lymphoid cell binding to islet endothelium. J Clin Invest 92:2509-2515

30. Hanninen A, Salmi M, Simell O, Jalkanen S (1993) Endothelial cell-binding properties of lymphocytes infiltrated into human diabetic pancreas. Implications for pathogenesis of IDDM. Diabetes 42:1656-1662

31. Hanninen A, Jaakkola I, Jalkanen S (1998) Mucosal addressin is required for the development of diabetes in nonobese diabetic mice. J Immunol 160:6018-6025

32. Faveeuw C, Gagnerault MC, Lepault F (1994) Expression of homing and adhesion molecules in infiltrated islets of Langerhans and salivary glands of nonobese diabetic mice. J Immunol 152:5969-5978

33. Faveeuw C, Gagnerault MC, Kraal G, Lepault F (1995) Homing of lymphocytes into islets of Langerhans in prediabetic non-obese diabetic mice is not restricted to autoreactive T cells. Int Immunol 7:1905-1913

34. Von Herrath MG, Oldstone MB (1997) Interferon-gamma is essential for destruction of beta cells and development of insulin-dependent diabetes mellitus. J Exp Med 185:531-539 
35. Savinov AY, Wong FS, Chervonsky AV (2001) IFN-gamma affects homing of diabetogenic T cells. J Immunol 167:66376643

36. Piali L, Weber C, LaRosa G et al (1998) The chemokine receptor CXCR3 mediates rapid and shear-resistant adhesioninduction of effector T lymphocytes by the chemokines IP10 and Mig. Eur J Immunol 28:961-972

37. Cardozo AK, Proost P, Gysemans C, Chen MC, Mathieu C, Eizirik DL (2003) IL-1beta and IFN-gamma induce the expression of diverse chemokines and IL-15 in human and rat pancreatic islet cells, and in islets from pre-diabetic NOD mice. Diabetologia 46:255-266

38. Ward SG, Bacon K, Westwick J (1998) Chemokines and T lymphocytes: more than an attraction. Immunity 9:1-11

39. Bonecchi R, Bianchi G, Bordignon PP et al (1998) Differential expression of chemokine receptors and chemotactic responsiveness of type $1 \mathrm{~T}$ helper cells (Th1s) and Th2s. J Exp Med 187:129-134

40. Christen U, McGavern DB, Luster AD, von Herrath MG, Oldstone MB (2003) Among CXCR3 chemokines, IFNgamma-inducible protein of $10 \mathrm{kDa}$ (CXC chemokine ligand [CXCL] 10) but not monokine induced by IFN-gamma (CXCL9) imprints a pattern for the subsequent development of autoimmune disease. J Immunol 171:6838-6845

41. Kim SH, Cleary MM, Fox HS, Chantry D, Sarvetnick N (2002) CCR4-bearing $\mathrm{T}$ cells participate in autoimmune diabetes. $\mathrm{J}$ Clin Invest 110:1675-1686
42. Lohmann T, Laue S, Nietzschmann U et al (2002) Reduced expression of Th1-associated chemokine receptors on peripheral blood lymphocytes at diagnosis of type 1 diabetes. Diabetes 51:2474-2480

43. Luster AD, Unkeless JC, Ravetch JV (1985) Gamma-interferon transcriptionally regulates an early-response gene containing homology to platelet proteins. Nature 315:672-676

44. Farber JM (1990) A macrophage mRNA selectively induced by gamma-interferon encodes a member of the platelet factor 4 family of cytokines. Proc Natl Acad Sci U S A 87:5238-5242

45. Campanella GS, Lee EM, Sun J, Luster AD (2003) CXCR3 and heparin binding sites of the chemokine IP-10 (CXCL10). J Biol Chem 278:17066-17074

46. Greening JE, Tree TI, Kotowicz KT et al (2003) Processing and presentation of the islet autoantigen GAD by vascular endothelial cells promotes transmigration of autoreactive T-cells. Diabetes 52:717-725

47. Christen U, Benke D, Wolfe T et al (2004) Cure of prediabetic mice by viral infections involves lymphocyte recruitment along an IP-10 gradient. J Clin Invest 113:74-84

48. Leppink DM, Bishop DK, Sedmak DD et al (1989) Inducible expression of an endothelial cell antigen on murine myocardial vasculature in association with interstitial cellular infiltration. Transplantation 48:874-877 